\section{Abstractions}

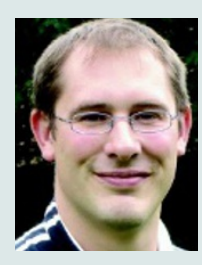

\section{FIRST AUTHOR}

One often-cited concern about global warming is that it could cause Greenland's ice sheet to melt. To better understand what controls the ice sheet's volume, researchers want to know how it first grew to cover much of Greenland around 3 million years ago. Existing theories implicate differing drivers of glaciation - including tectonic closure of the Panama seaway, uplift of the Rocky and Himalayan mountains, changes in El Niño-Southern Oscillation and variations in atmospheric carbon dioxide concentrations. Dan Lunt at the University of Bristol, UK, and his colleagues modelled each theory, and report that a significant fall in atmospheric $\mathrm{CO}_{2}$ concentrations (and, subsequently, cooler summers) drove ice-sheet growth (see page 1102). Lunt explains why he needs new clues to reconstruct past climates.

Was there a favoured theory at the outset of this work?

One popular hypothesis is that the closure of the Panama seaway caused a rise in the salinity gradient between the Pacific and Atlantic oceans, changing ocean circulation and ultimately enhancing snowfall over Greenland. It's popular because data from the Caribbean and North Atlantic indicate that the closure coincided with glaciation.

What is new about your approach? First, we used a state-of-the-art climate model that takes months to simulate ocean, atmosphere and vegetation components. But climate models do not include variations in topography, which are important to glaciation dynamics. So we also used a highresolution ice-sheet model to resolve the dynamics of ice formation at high altitudes.

Was there a Eureka moment? Yes. I was blown away when the models produced a map of a huge Greenland ice sheet under low $\mathrm{CO}_{2}$ conditions, which we hadn't expected. Now we need more indicators of the range of past $\mathrm{CO}_{2}$ concentrations to better model past climate.

Don't ice cores provide that information? Ice cores are amazing records, but those we have stop about 650,000 years ago. There is no direct record further back in time, and proxy indicators of $\mathrm{CO}_{2}$, such as marine sediment isotopes, are open to interpretation. We need multiple indicators to confirm past $\mathrm{CO}_{2}$ values. The search is on!

Which past climate era most interests you? This period of the Pliocene, about 3 million years ago. Because we are now approaching the same atmospheric $\mathrm{CO}_{2}$ levels seen then - about 400 parts per million - it provides a potential analogue of future climate change.

\section{MAKING THE PAPER}

\section{Ernst Fehr}

\section{Children's sense of fairness makes them egalitarian but not generous.}

Several years ago, Ernst Fehr returned from a trip with gifts for his four-year-old son and eight-year-old daughter. Fehr, an economist at the University of Zurich who studies the evolution of human cooperation, had removed the price tags so that the children would not rate one gift more highly than the other. But when they began measuring the boxes with a ruler to see which was larger, and - in their view - better, he wondered at what age children begin to understand the concept of fairness.

"Three-year-olds will use the language of fairness, but mainly to their own advantage and to support their egoism," says Fehr. Benevolence and sensitivity toward others are critical virtues that allow humans to cooperate with genetically unrelated individuals. But little was known about when young children begin to take account of the welfare of others.

To find out, Fehr and his colleagues enlisted the help of some pint-sized participants from playgroups, kindergartens and primary school classes. They designed three experiments that would measure the children's 'other-regarding' preferences, using Smarties, Jelly Babies and Fizzers as appealing currency.

In each test a child was asked to choose between two actions: the 'equal shares' choice of taking one packet of sweets for themselves and one for their partner, or an alternative that tested aspects of regard for others - 'prosocial' behaviour (actions that benefit another; in which the alternative choice was no sweets for their partner), 'envy' (in which the alternative choice was one packet for the child and two for their partner), and 'sharing' (in which the other choice was two for the child and none for their partner).

They found that young children develop a particular form of other-regarding behaviour,

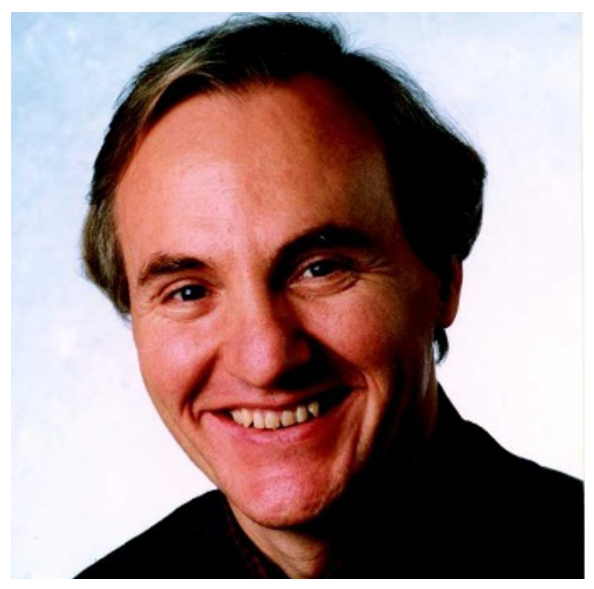

called inequality aversion, between the ages of three and eight. On average, three- and fouryear-olds behave selfishly whereas seven- and eight-year-olds prefer situations that remove the inequality (see page 1079). "It's not simple generosity, it is egalitarianism," says Fehr. "If the other child has less, then I'm willing to give, but I don't want the other child to have more than me either."

Fehr says he was surprised by how strongly egalitarianism increases with age, particularly in the envy game. Almost $90 \%$ of seven- and eight-year-old children prefer to distribute the sweets equally rather than give their partner extra. Also surprising was that $15-20 \%$ of the children minimized their partner's payoff in all three games. Such 'spiteful' behaviours are also seen in about $10-15 \%$ of adults. "These children could be an interesting group to study. Maybe spiteful adults have spiteful children," he says.

The researchers made some interesting observations outside of the tests. They sent the parents a questionnaire that asked about the child's siblings, birth order and his or her ability to feel empathy. The package included a payoff of sorts - extra postage stamps, "something that every parent could use", says Fehr - to encourage parents to return the questionnaire. "Thank you for the stamps," some of the parents wrote back. "The interesting thing," says Fehr, "is that the children of those parents who wrote a thank you note were more prosocial."

\title{
FROM THE BLOGOSPHERE
}

Calling all science tourists! Inspired by the exotic research locales of two News Features last week, a Nature Network forum asks, "What did you do with your summer holiday?"

One feature treks to coastal Chile to record the return of jumbo squid, prized by neuroscientists for their giant nerve axons (Nature 454, 934936; 2008). The other visits a remote volcanic island where scientists are studying a fragile ecosystem that is literally emerging out of the Indian Ocean (Nature 454, 930-932; 2008).

The author of this column enjoyed a brief sojourn at the northern Californian rock pools and beaches immortalized by John Steinbeck, observing the behaviour of the wild pelicans and elephant seals.

There are those for whom science is life, and a vacation is just an opportunity to do science elsewhere. What we really want to know is how you spent your summer holiday. Let us know your own sciencerelated vacation experiences over at Nature Network (http:// tinyurl.com/59uqpn). The more unusual the better: who knows, your tale might end up as the basis for a future Nature News Feature. 